\title{
(C) OPEN ACCESS \\ Chronic electronic cigarette exposure in mice induces features of COPD in a nicotine-dependent manner
}

\author{
Itsaso Garcia-Arcos, ${ }^{1,2}$ Patrick Geraghty, ${ }^{1,2}$ Nathalie Baumlin, ${ }^{3}$ Michael Campos, ${ }^{3}$ \\ Abdoulaye Jules Dabo, ${ }^{1,2}$ Bakr Jundi, ${ }^{4}$ Neville Cummins, ${ }^{5}$ Edward Eden, ${ }^{5}$ \\ Astrid Grosche, ${ }^{3}$ Matthias Salathe, ${ }^{3}$ Robert Foronjy ${ }^{1,2}$
}

- Additional material is published online only. To view please visit the journal online (http://dx.doi.org/10.1136/ thoraxjnl-2015-208039).

For numbered affiliations see end of article.

\section{Correspondence to} Dr Robert Foronjy, Division of Pulmonary and Critical Care Medicine, SUNY Downstate Medical Center, Brooklyn, NY 11203, USA; Robert. Foronjy@downstate.edu

IG-A and PG contributed equally.

MS and RF shared senior authorship.

Received 6 November 2015 Revised 12 July 2016 Accepted 27 July 2016 Published Online First 24 August 2016

\section{SLinked}

- http://dx.doi.org/10.1136/ thoraxjnl-2016-209273

\section{CrossMark}

\author{
To cite: Garcia-Arcos I, \\ Geraghty P, Baumlin N, \\ et al. Thorax
}

2016;71:1119-1129.

\section{ABSTRACT}

Background The use of electronic (e)-cigarettes is increasing rapidly, but their lung health effects are not established. Clinical studies examining the potential long-term impact of e-cigarette use on lung health will take decades. To address this gap in knowledge, this study investigated the effects of exposure to aerosolised nicotine-free and nicotine-containing e-cigarette fluid on mouse lungs and normal human airway epithelial cells.

Methods Mice were exposed to aerosolised phosphate-buffered saline, nicotine-free or nicotinecontaining e-cigarette solution, 1-hour daily for 4 months. Normal human bronchial epithelial (NHBE) cells cultured at an air-liquid interface were exposed to e-cigarette vapours or nicotine solutions using a Vitrocell smoke exposure robot.

Results Inhalation of nicotine-containing e-cigarettes increased airway hyper-reactivity, distal airspace enlargement, mucin production, cytokine and protease expression. Exposure to nicotine-free e-cigarettes did not affect these lung parameters. NHBE cells exposed to nicotine-containing e-cigarette vapour showed impaired ciliary beat frequency, airway surface liquid volume, cystic fibrosis transmembrane regulator and ATP-stimulated $\mathrm{K}+$ ion conductance and decreased expression of FOXJ1 and KCNMA1. Exposure of NHBE cells to nicotine for 5 days increased interleukin (IL)- 6 and IL-8 secretion. Conclusions Exposure to inhaled nicotine-containing e-cigarette fluids triggered effects normally associated with the development of COPD including cytokine expression, airway hyper-reactivity and lung tissue destruction. These effects were nicotine-dependent both in the mouse lung and in human airway cells, suggesting that inhaled nicotine contributes to airway and lung disease in addition to its addictive properties. Thus, these findings highlight the potential dangers of nicotine inhalation during e-cigarette use.

\section{INTRODUCTION}

Exposure to cigarette smoking is the leading cause of preventable death in the USA. The majority of COPD deaths are associated with smoke exposure, with COPD now ranking as the third leading cause of death in the USA ${ }^{1}$ and it is projected to become the third leading cause worldwide within the next 20 years. $^{2}$ Quitting smoking lowers the risk for several diseases and can increase life expectancy. ${ }^{2}$ Though smoking prevalence in the USA has decreased over the past 50 years, approximately

\section{Key messages}

What is the key question?

- What are the pulmonary consequences of electronic (e)-cigarette inhalation?

\section{What is the bottom line?}

- These findings show that the inhalation of nicotine present in e-cigarettes alters inflammation, ion conductance and mucociliary function in human bronchial epithelial cells and induces airway hyper-reactivity and air space enlargement in exposed mice.

\section{Why read on?}

- This study provides insights into the lung health effects of e-cigarettes and also implicates nicotine as a causative factor at the onset and progression of COPD.

$19 \%$ of the population continues to smoke. ${ }^{3}$ Though nicotine replacement therapy (NRT) helps, nearly $93 \%$ of smokers will relapse despite NRT within 6 months of quitting. ${ }^{4}$ Given these difficulties with smoking cessation and the enormous public health burden imposed by COPD, some healthcare advocates have argued that electronic (e)-cigarettes are a safer alternative for those individuals who cannot quit. ${ }^{5}$

e-Cigarettes are devices that effectively deliver vaporised liquid nicotine to the lungs. The user can choose the nicotine concentration of e-cigarette liquid (e-liquid) that is loaded into the device's cartridge. When the user inhales, the e-liquid, primarily nicotine in propylene glycol (PG) or vegetable glycerine (VG), is heated to produce a vapour that is inhaled into the lungs. Despite the many flavours and varieties available, almost all consumers choose e-liquids that contain nicotine. ${ }^{6}$ Recent studies indicate that e-cigarette exposure could pose several future health problems. The use of ecigarettes enhances oxidative stress and inflammation in mice $^{7}$ and impairs immune defence against bacterial and viral infection. ${ }^{8}$ This also has implications in secondhand smoke exposure as e-cigarettes significantly increase the nicotine content of indoor air and expose non-users to secondhand vapours. ${ }^{9}$ Nicotine enhances airway hyper-reactivity in 
lipopolysaccharide-challenged mice and inflammation in lung epithelial cells. ${ }^{10}$ Nicotine also suppresses apoptosis in lung tumours. ${ }^{11}$ However, the biological effects of nicotine delivered to the lungs by e-cigarettes have not been thoroughly studied.

Here, we used in vitro and in vivo models to evaluate the biological impact of e-cigarette usage on mouse lungs and in normal human bronchial epithelial (NHBE) cells collected from a series of human subjects. This study found that inhaled nicotine in e-cigarettes triggered effects associated with the pathogenesis and progression of COPD: airspace enlargement, mucous cell hypertrophy, release of inflammatory mediators and altered epithelial ciliary function. The data collected provide direct evidence of the potential harmful effects of e-cigarettes and, in particular, nicotine inhalation into the lung.

\section{METHODS}

In vivo inhaled exposure to e-cigarette fluids

All animal experiments were performed with approval from Mount Sinai Roosevelt Medical Center's Institutional Animal Care and Use Committee. We developed an in vivo e-cigarette exposure model using an mouse pie cage (MPC) Aerosol Medication Nebulizer (Braintree Scientific, Braintree, Massachusetts, USA). For 4 months (5 days/week), A/J mice aged 12 weeks (Jackson labs) were whole body exposed to $0.4 \mathrm{~mL}$ of phosphate-buffered saline (PBS) or e-cigarette vehicle (PG and VG 50/50; American eLiquid Store) containing 0 or $18 \mathrm{mg} / \mathrm{mL}$ nicotine (American eLiquid Store). All liquids were preheated to $37^{\circ} \mathrm{C}$ prior to nebulisation and the exposures lasted 1 hour. Mice were euthanised 24 hours after the last exposure. Bronchoalveolar lavage fluid (BALF) was collected and immune cells quantified as previously described. ${ }^{12}$ Plasma cotinine levels were measured using a commercially available kit and following the manufacturer's instructions (Abnova, Walnut, California, USA).

\section{Airway responses to methacholine challenge}

Airway responses to increasing doses of methacholine (Sigma Chemical, St. Louis, Missouri, USA) were assessed with the Scireq Flexivent system (Scireq, Montreal, Quebec, Canada) in mice exposed to 4 months of PBS and e-liquid containing 0 or $18 \mathrm{mg} / \mathrm{mL}$ nicotine. Animals were anaesthetised with ketamine/ xylazine $(10 \mathrm{mg} / \mathrm{kg})$ and paralysis was induced with $1 \mathrm{mg} / \mathrm{kg}$ pancuronium bromide intraperitoneally. Baseline pulmonary function measurements (forced expiratory flow at 50\% of FVC $\left.\left(\mathrm{FEF}_{50}\right)\right)$ were determined prior to methacholine challenge in mice. The linear single-compartment model was used to assess total respiratory system resistance.

\section{Histological analysis}

The lungs underwent pressure-fixation and fixed tissue was processed and H\&E stained for analysis of morphometry as previously described. ${ }^{13}$ Mucin was stained with Alcian blue and counterstained with Safranin O using a commercially available kit (Abcam, Cambridge, Massachusetts, USA). For immunofluorescence, slides were blocked with $10 \%$ goat serum in PBS for 1 hour at room temperature. The slides were incubated with primary antibody (rabbit polyclonal anti-MUC5AC IgG, 1:50 dilution; Santa Cruz Bio) or rabbit IgG negative control in 5\% goat serum $1 \%$ bovine serum albumin in PBS overnight at $4^{\circ} \mathrm{C}$ and then with secondary antibody (donkey antirabbit IgG-546, 1:200 dilution) for 1 hour at room temperature. Immunoreactivity was visualised with an epifluorescence microscope. Tissue quantification of macrophages, neutrophils and lymphocytes were detected on slides with primary antibodies; rabbit polyclonal anti-MAC3, antineutrophil elastase or
anti-CD3 IgG (Abcam; 1:50 dilution). Immune cells were quantified from 10 randomly selected $\times 400$ images of the lung tissue sections from each mouse.

\section{Cell viability analysis}

Apoptosis was determined on paraffin-embedded tissue by the terminal deoxynucleotidyl transferase dUTP nick end-labelling (TUNEL) in situ cell death detection kit AP (Roche Diagnostics), following the manufacturer's instructions. For each lung, 10 random sections were obtained at three different depths of tissue sectioning and a minimum of 1000 cells/section were visually evaluated after staining. The positively labelled cells were expressed as a percentage of total nuclei. Caspase 3/7 activity was measured as previously described, ${ }^{14}$ using a commercially available Caspase-Glo 3/7 Assay System (Promega, Fitchburg, Michigan, USA). In vitro cell viability was determined by lactate dehydrogenase (LDH) released into media using a commercially available assay (Sigma Aldrich).

\section{qPCR, MMP and cytokine protein detection}

RNA was isolated using the Qiagen RNeasy kit and complementary DNA (cDNA) was reverse transcribed using the Applied Biosystems high-capacity cDNA kit. qPCR was performed on the Bio-Rad CFX384 real-time system using validated TaqMan probes (Life Technologies/Applied Biosystems). qPCR results are represented as relative quantification. Gene expression was normalised to $\beta$-actin or glyceraldehyde 3-phosphate dehydrogenase (GAPDH).

Cytokine protein levels were measured in culture media using a beads assay on a Bio-Rad Bio-Plex 200 system (Bio-Rad, Hercules, California, USA). Collagenase units were calculated as the number of $\mu$ moles of leucine liberated per mg of enzyme, by a colorimetric ninhydrin method. ${ }^{15}$ Cathepsin activity assays were performed as previously described. ${ }^{16}$

\section{Immunoblot analysis}

Lung tissue was homogenised in four volumes of radioimmunoprecipitation assay buffer. Equal concentrations of protein were immunoblotted for phosphorylated PKC $\alpha$ (p-PKC $\alpha$ ), PKC $\alpha$, phosphorylated extracellular regulated kinase (ERK), ERK and $\beta$-actin (Cell Signaling Technology, Danvers, Massachusetts, USA). Chemiluminescence was detected and quantified with a Molecular Imager ChemiDoc XRS + (Bio-Rad). Densitometry was performed and represented as a ratio of pixel intensity of the phosphorylated protein compared with total protein, using Bio-Rad Laboratories Image Lab software (V.4.0, build 16).

\section{In vitro analyses of NHBE cells}

NHBE cells were isolated from appropriately consented donors whose lungs were found unsuitable for transplantation. The 15 donors were non-smokers with no known airway diseases, 5 females and 10 males aged $25-58$ years. From a racial aspect, there were 10 Caucasians, 2 African-Americans, 1 Hispanic white and 2 unknowns. After expansion, cells were redifferentiated at the air-liquid interface (ALI) on collagen-coated 12-mm Transwell inserts (Corning, Lowell, Massachusetts, USA). ${ }^{17-19}$ The cells were exposed to 36 puffs of vaporised e-liquid either containing 0 or $36 \mathrm{mg} / \mathrm{mL}$ nicotine using the VC-1 exposure system (Vitrocell Systems, Waldkirch, Germany), with a $70 \mathrm{~mL}$ puff volume applied every $30 \mathrm{~s}$. Cells were also exposed to nicotine $(0$ or $100 \mu \mathrm{M}$, with an estimated final $100 \mathrm{nM}$ nicotine concentration in the airway surface liquid (ASL) after nebulisation) aerosolised in the Cloud system 
(Vitrocell Systems) or baseolaterally supplemented nicotine $(0,1$ or $10 \mu \mathrm{M}$ ) for 12 hours or 5 days.

\section{Ion channel function and mucociliary clearance}

Short-circuit currents (Isc) and ciliary beat frequency (CBF) were recorded at the following time points: 8 hours after vapour exposure in the VC-1 system, 4 hours after nebulised nicotine in the Cloud system and 12 hours after basolateral addition of nicotine. ${ }^{20}$ Cystic fibrosis transmembrane regulator (CFTR) function was determined by the decrease in Isc after addition of CFTR-inh in cells stimulated with $10 \mu \mathrm{M}$ forskolin in the presence of $10 \mu \mathrm{M}$ amiloride at room temperature. Apical, ATP-stimulated $\mathrm{K}+(\mathrm{BK})$ currents were measured as previously described. ${ }^{20}$

\section{Measurement of ASL and percent ciliated surface}

Twenty-four hours after exposure of cells on $12 \mathrm{~mm}$ inserts to 36 puffs of e-cigarette vapour with 0 or $36 \mathrm{mg} / \mathrm{mL}$ nicotine in the VC-1 exposure system, the cultures were imaged with an Epson flatbed scanner and images were analysed for meniscus volume using ImageJ software (National Institutes of Health, Bethesda, Maryland, USA), kindly provided by Michael Myerburg (University of Pittsburgh). Fully redifferentiated NHBE cells were fixed, blocked and stained with a monoclonal antitubulin acetylated antibody (1:10 000 dilution; Sigma Aldrich) to detect cilia. The \% ciliated area was determined using ImageJ software.

\section{Statistical analyses}

F-tests, D'Agostino-Pearson Omnibus normality tests, nonparametric Friedman test and Student's t-test were performed on all data sets. One-way analysis of variance was used for comparisons of more than two groups followed by a post hoc test for linear trend analysis on human cell samples. Data are represented as dot plots with a line denoting the mean and bars denoting the SEM. GraphPad Prism Software (GraphPad, La Jolla, California, USA) was used for all data analysis and graphical representations.

\section{RESULTS}

Exposure to inhaled nicotine-containing e-cigarette fluids induces airway hyper-reactivity and airspace enlargement

Mice were exposed to aerosolised PBS and e-liquid $(0$ and $18 \mathrm{mg} / \mathrm{mL}$ nicotine) daily for 4 months. Exposure to aerosolised nicotine-containing e-cigarettes increased plasma cotinine, the nicotine degradation product, demonstrating that nicotine was effectively delivered to the lungs and absorbed systemically by the mice (figure 1A). Airway hyper-reactivity was assessed by methacholine challenge test. At every methacholine dose $\geq 1 \mathrm{mg} /$ $\mathrm{mL}$, mice exposed to nicotine-containing e-cigarette fluids showed significantly higher respiratory resistance than mice exposed to aerosolised PBS or to e-cigarette fluids that did not contain nicotine (figure $1 \mathrm{~B}$ and online supplementary figure $\mathrm{S} 1$ ). No differences in airway hyper-reactivity were found in mice exposed to nicotine-free e-cigarette fluids when compared with mice exposed to PBS. To examine baseline lung function changes due to e-cigarette use, forced expiratory flow at 50\% $\left(\mathrm{FEF}_{50}\right)$ of $\mathrm{FVC}$ was determined. The $\mathrm{FEF}_{50} / \mathrm{FVC}$ ratio was significantly reduced from $23 \pm 1.2$ in mice exposed to nicotinefree e-cigarette fluids to $15 \pm 1.5$ in mice exposed to e-cigarettes containing $18 \mathrm{mg} / \mathrm{mL}$ nicotine (average \pm SEM; $\mathrm{p}<0.01$ ), suggesting obstruction of the small airways (figure 1C).

Mice exposed to inhalation of nicotine-containing e-cigarette fluids showed significant airspace enlargement, while nicotine-free e-cigarette fluids or PBS exposure had no impact on lung architecture (figure 1D). Mean linear intercept, surface area/unit volume ratio and fractional volume were calculated in H\&E-stained lung sections. All three parameters were altered in the mice exposed to nicotine-containing e-cigarette fluids: mean linear intercept was increased and surface area/unit volume and fractional volume were decreased ( $p<0.05$ for all; figure 1D). No difference in any of these parameters was observed between mice exposed to nicotine-free e-cigarette fluids or PBS (figure 1D).

Nicotine inhalation enhanced inflammatory cell infiltration into the lung. After 2 weeks of exposure, BALF cells increased from $130000 \pm 27000$ cells/mouse in the mice exposed to nicotine-free e-cigarette fluids to $280000 \pm 41000 \mathrm{cells} /$ mouse in the mice exposed to nicotine-containing e-cigarette fluids $(p<0.01$; mean \pm SEM; online supplementary figure S2D). After 4 months of exposure, mice exposed to nicotine-containing ecigarette fluids showed a trend towards increased cell number in BALF (figure 2A). Cytospins showed that macrophages were the most abundant cell type recovered in the bronchoalveolar lavage in all three conditions, while neutrophil and lymphocytes constituted a minor proportion (figure 2A). Macrophages were observed in the alveolar space in all mouse groups (figure 2B) and quantification of tissue inflammation demonstrated that elevated macrophage numbers in lung tissue of mice subjected to nicotine-containing e-cigarette fluids compared with the other groups (figure 2C). Neutrophil and lymphocyte numbers were not altered (figure 2C).

\section{Nicotine in e-cigarette fluids triggers mucin production and apoptosis}

Airway mucin production increased in mice exposed to nicotinecontaining e-cigarette fluids, as shown by Alcian blue staining and fluorescence microscopy for MUC5AC (figure 3A). Mice exposed to nicotine-containing e-cigarette fluids showed a twofold increase in $M u c 5 a c$ gene expression $(\mathrm{p}<0.01$; figure $3 \mathrm{~A})$. Apoptosis of structural cells in the lung is another important event in the pathogenesis of COPD. ${ }^{21}$ Apoptosis, as estimated by TUNEL staining, increased within the alveoli and the airway epithelium of mice exposed to e-cigarette fluids that contained nicotine (figure 3B). Caspase 3/7 activity, increased from $37 \pm 1.5$ units of luminescence in nicotine-free e-cigarette fluid exposed mice to $53 \pm 4.7$ units of luminescence in nicotinecontaining e-cigarette fluid exposed mice $(\mathrm{p}<0.01$; mean \pm SEM; figure $3 \mathrm{~B}$ ). Taken together, nicotine in e-cigarettes promotes airway hyper-reactivity, inflammation, airway enlargements, mucus production and lung cell apoptosis.

\section{E-cigarette fluids containing nicotine induce lung cytokine and protease expression}

Expression of several cytokines and proteases associated with tissue remodelling was measured in lung homogenates after 2 weeks (see online supplementary figure S2A-C) and 4 months of exposure (figure 4). Compared with exposure to inhaled e-cigarette fluids that lacked nicotine $(0 \mathrm{mg} / \mathrm{mL})$, e-cigarette fluid containing nicotine $(18 \mathrm{mg} / \mathrm{mL})$ caused a significant increase in the expression of Il-1 $\beta$, monocyte chemoattractant protein-1 (MCP-1), Cxcl10, Il-6 and Cxcl2 $(\mathrm{p}<0.05$ for all; figure 4A). Matrix metalloproteinase (MMP)-9 and MMP-12 and cathepsins $K$ and $L 1$ also showed increased messenger RNA expression in the mice exposed to e-cigarette fluids containing nicotine (figure 4B). Collagenase BALF activity increased by $70 \%(\mathrm{p}<0.03)$ and cathepsin BALF activity showed a trend towards an increase in the BALF of mice exposed to e-cigarette fluids that contained nicotine (figure 4C). Expression of Mcp-1, Muc5ac and CatK showed similar patterns after 2 weeks of exposure to nicotine- 
Figure 1 Lung function in mice exposed to inhaled phosphate-buffered saline (PBS), nicotine-free and nicotine-containing e-cigarette fluids. Mice were exposed daily to inhaled $\mathrm{PBS}$, nicotine-free (EC vehicle, $0 \mathrm{mg} /$ $\mathrm{mL}$ ) or nicotine-containing (EC vehicle, $18 \mathrm{mg} / \mathrm{mL}$ ) e-cigarette fluid for 4 months and nicotine absorption was confirmed by (A) plasma cotinine levels. (B) Airway hyperresponsiveness to increasing doses of methacholine was assessed in each animal group. (C) Negative pressure-driven forced expiratory and forced oscillation technique manoeuvres were performed to determine changes in pulmonary mechanics in all animal groups. Forced expiratory flow at $50 \%$ of FVC $\left(\mathrm{FEF}_{50}\right)$ were determined in each animal. (D) Representative H\&E-stained images of fixed lung parenchyma from mice exposed daily for 4 months (scale bar $=100 \mu \mathrm{m}$ ) and quantification of surface area/unit volume, fractional volume and mean linear intercept. Graphs are represented as mean \pm SEM of three measurements. $p$ Values shown, comparing both treatments connected by a line. All $n \geq 6$ per group. The comparisons between two individual groups were determined by Student's t-test. EC, e-cigarette.
A
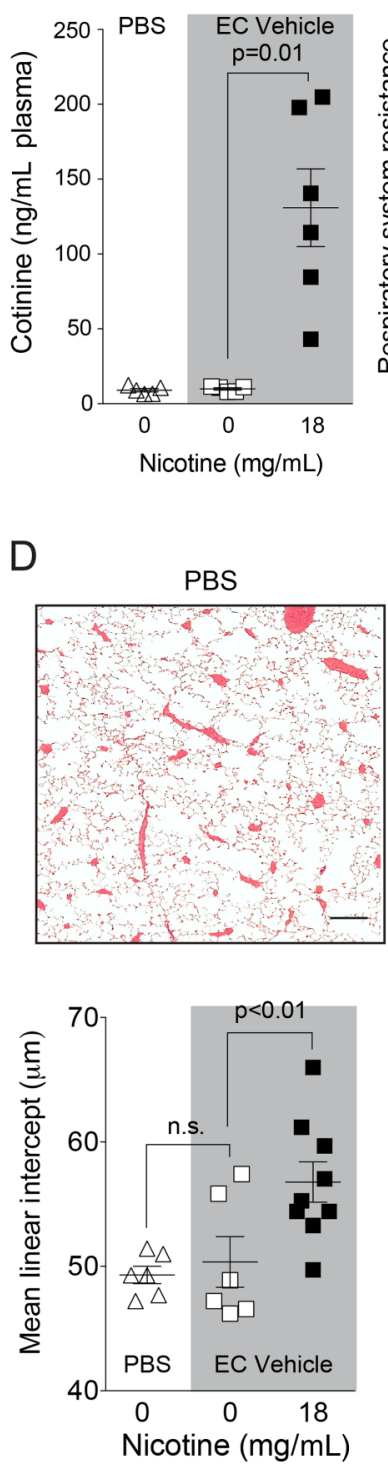

B

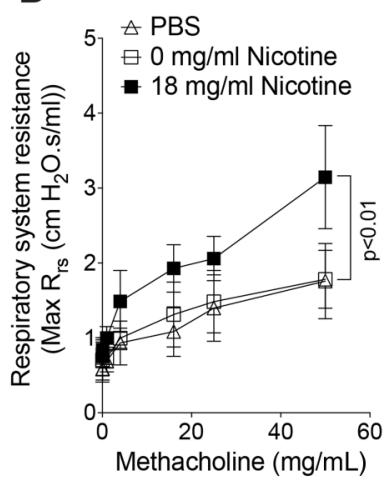

C

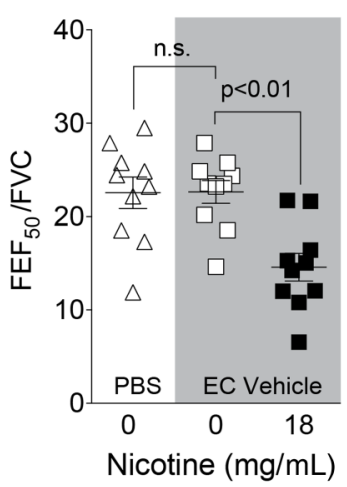

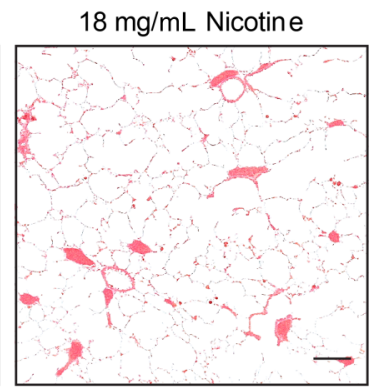
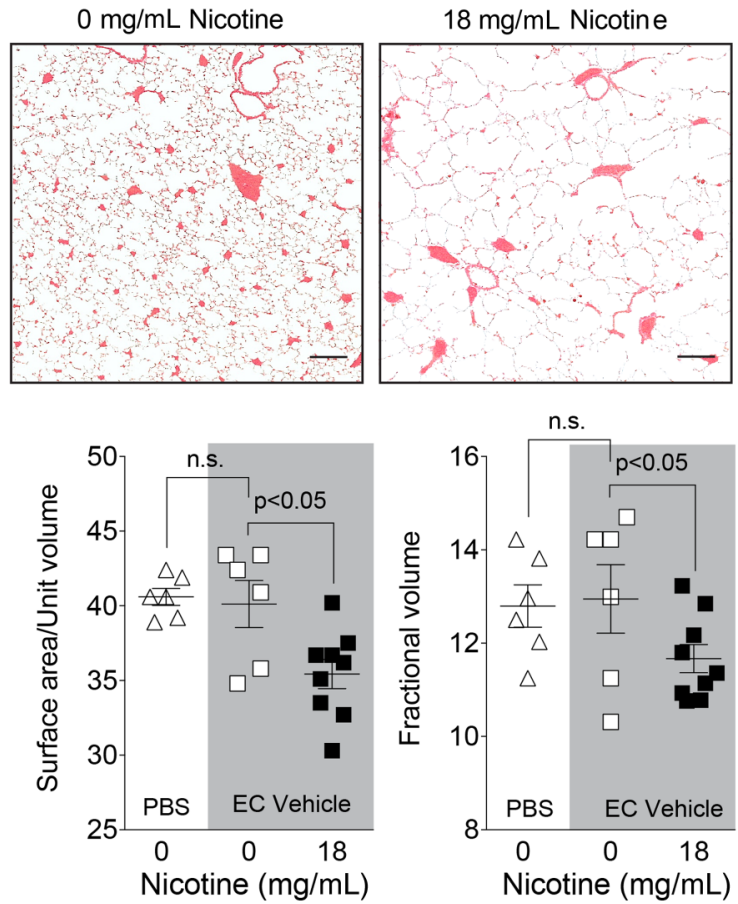

containing e-cigarettes (see online supplementary figure S2). Our findings indicate that inhalation of nicotine via e-cigarette fluids can induce cytokine and protease expression and activity in a similar manner to tobacco cigarette smoke exposure.

\section{Inhalation of nicotine in e-cigarette fluids activates PKCo/ERK signalling in the lung}

Our laboratory has previously shown that activation of PKC $\alpha$ and ERK by cigarette smoke regulated lung inflammation and protease responses. ${ }^{22}$ Since nicotine can stimulate the $\alpha$-7-nicotinic receptor $(\alpha 7 \mathrm{nAchR})$ upstream of PKC $\alpha$ and ERK in human lung epithelial cells, ${ }^{11}{ }^{23}$ we asked whether nicotine in e-cigarette fluids would activate this signalling mechanism. Lung homogenates from mice exposed to nicotine in e-cigarette fluids showed increased phosphorylation of PKC $\alpha$ and a trend increase in lung phosphorylation of ERK (figure 5). Of note, inhibition of this pathway prevents airspace enlargement in the lungs of cigarette smoke-exposed mice. ${ }^{22}$

\section{The nicotine present in e-cigarette fluids alters ciliary} function and cytokine production in NHBE cells

We used fully differentiated cultures of NHBE cells to assess the impact of nicotine-containing e-cigarette vapour on ciliary function. NHBE cells were obtained from healthy donors, cultured at the ALI and exposed to nicotine-free or to nicotinecontaining e-cigarette vapours (figure 6A). Exposure to vaporised e-cigarette vapour had no effects on NHBE cell viability, determined by LDH assays (see online supplementary figure S3A). Ciliary beating serves as one of the main defence functions of the airways. ${ }^{24}$ Cells exposed to nicotine-containing e-cigarette vapours had significantly reduced $\mathrm{CBF} 8$ hours after exposure $(5.2 \pm 0.5 \mathrm{~Hz}$ vs $2.6 \pm 1 \mathrm{~Hz} ; \mathrm{p}=0.01 ; \mathrm{p}<0.05$; figure $6 \mathrm{~B})$. Since exposure to nicotine in e-cigarettes reduced CBF, the per cent of cilia on the apical cell surface was determined on NHBE cells. There was no significant difference in percentage of ciliary area on the apical surface 24 hours after exposure to nicotine-containing e-cigarette vapour (figure 6C). However, the gene expression of a major regulator of ciliogenesis, FOXJ1, was reduced in cells exposed to nicotine-containing e-cigarette vapours (figure 6D). Ion channel conductance for CFTR was significantly reduced in cells exposed to nicotine-containing e-cigarette vapours 8 hours after exposure (figure $6 \mathrm{E}$ ), and was independent of the expression of the CFTR gene (figure 6F). Ion channel conductance for the $\mathrm{BK}$ channel was also significantly reduced in cells exposed to nicotine-containing e-cigarette vapours at 8 hours after exposure (figure 6G), which 
Figure 2 Lung inflammation in mice exposed to inhaled phosphate-buffered saline (PBS) and to nicotine-free e-cigarette fluids. Mice were exposed daily to inhaled PBS, nicotine-free $(0 \mathrm{mg} / \mathrm{mL})$ or nicotine-containing (18 $\mathrm{mg} / \mathrm{mL}$ ) e-cigarette fluids for 4 months. (A) Total bronchoalveolar lavage fluid cells, macrophages, neutrophils and lymphocytes were quantified in mice exposed daily for 4 months. (B) Representative H\&E-stained images of fixed lung parenchyma and macrophages from mice exposed daily for 4 months (scale bar $=20 \mu \mathrm{m}$ ). (C) Tissue cellularity was quantified by measuring the average number of macrophages, neutrophils or lymphocytes per high powered field $(\times 400)$. Ten randomly selected high powered images were used for quantification per mouse. Graphs are represented as mean \pm SEM of three measurements. $p$ Values shown, comparing both treatments connected by a line. All $n \geq 7$ per group. The comparisons between two individual groups were determined by Student's t-test. BALF, bronchoalveolar lavage fluid. EC, e-cigarette.

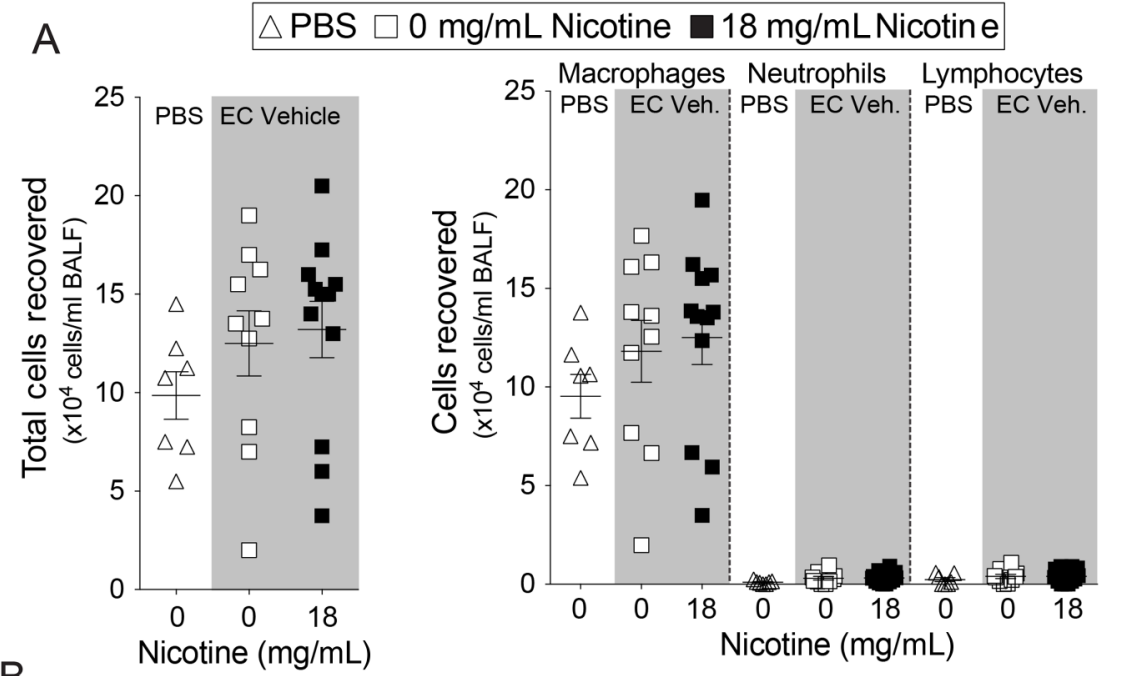

B

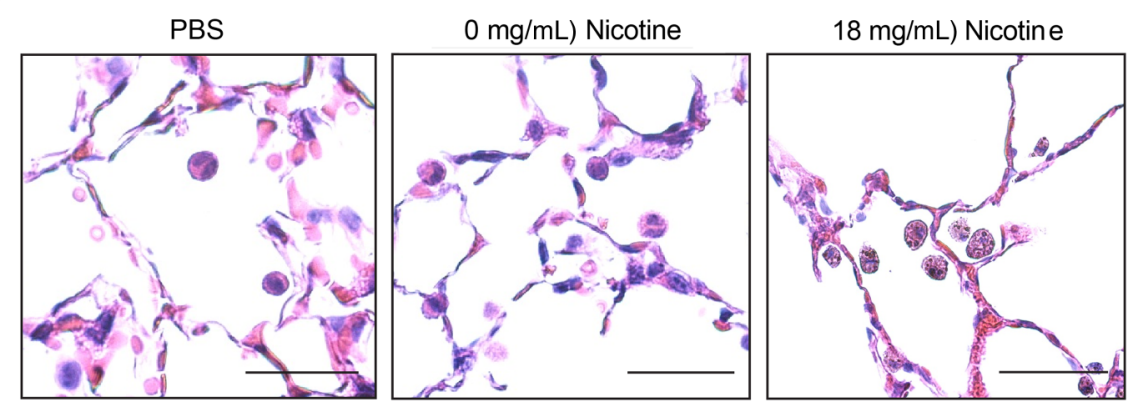

C
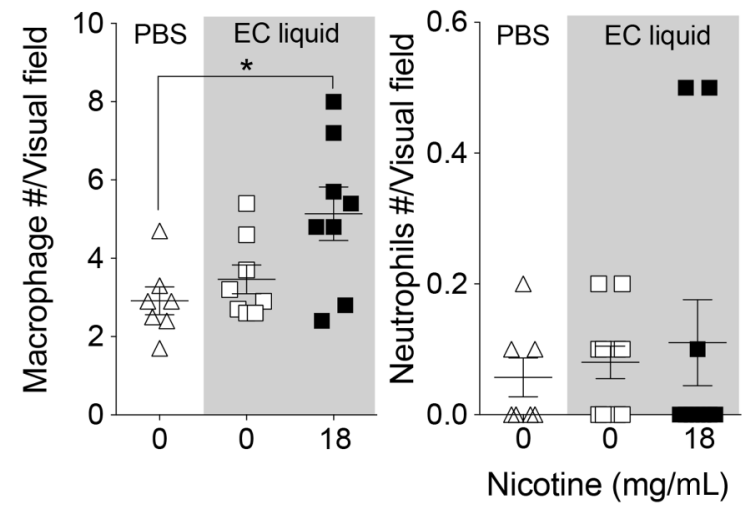

coincided with reduced expression of BK channel $\alpha$ subunit (KCNMA1) gene that regulates ASL. ${ }^{25}$ ASL volume changes showed a significant decrease, from $14.6 \pm 2 \mu \mathrm{L}$ in cells exposed to nicotine-free e-cigarette vapour at 24 hours after exposure to $3.8 \pm 1 \mu \mathrm{L}$ in cells exposed to nicotine-containing e-cigarette vapour (mean $\pm S E M ; p<0.01$; figure $6 \mathrm{I})$. Therefore, nicotine in e-cigarette vapour directly influences ciliary function.

\section{Nicotine directly alters ciliary function and cytokine production in NHBE cells}

To examine how nicotine alone affected ion transport and CBF, NHBE cells were exposed to 0 or $100 \mu \mathrm{M}$ nicotine nebulised $(200 \mu \mathrm{L})$ into a chamber (Cloud from Vitrocell) (figure 7A). Using a Vitrocell microbalance, we determined that there was a total deposition of $25 \mathrm{~nL}$ in each well of our tissue culture plates. Assuming an ASL volume at baseline of about $40 \mu \mathrm{L}$, we calculated that the effective nicotine concentration would reach $60-120 \mathrm{nM}$ in the apical surface liquid of these cells grown at
ALI. Exposure to aerosolised nicotine had no effects on NHBE cell viability at 4 hours after nebulisation (see online supplementary figure S3B). Cells exposed to aerosolised nicotine showed decreased CFTR and BK conductance at 4 hours after exposure (figure 7B, C).

To analyse the effects of long-term exposure to nicotine, NHBE cells were exposed to basolateral media supplemented with 0,1 or $10 \mu \mathrm{M}$ nicotine for 5 days (figure $8 \mathrm{~A}$ ). Exposure to nicotine in the culture media for 5 days had no effects on NHBE cell viability (see online supplementary figure S3C). In cells exposed to $10 \mu \mathrm{M}$ nicotine in the culture media, CBF decreased from 7.2 \pm 0.3 in controls to $6.2 \pm 0.3$ (mean \pm SEM; $\mathrm{p}<0.05$; figure $8 \mathrm{~B}$ ) and there was a decreasing trend in the CFTR activity (figure 8C). Media nicotine supplementation also increased cytokine release both to the basolateral and the apical sides of the NHBE cell cultures at concentrations of $10 \mu \mathrm{M}$ : interleukin (IL)-6 concentration in the wash increased from 390 to $442 \mathrm{pg} / \mathrm{mL}$ ( $\mathrm{p}<0.05$; median). IL- 8 and MCP-1 also showed 
Figure 3 Histological analysis of lungs from mice exposed to inhaled nicotine-free and nicotine-containing e-cigarette aerosol. Mice were exposed daily to inhaled nicotine-free $(0 \mathrm{mg} /$ $\mathrm{mL}$ ) or nicotine-containing $(18 \mathrm{mg} / \mathrm{mL})$ e-cigarette aerosol for 4 months. Then, lungs were fixed and sectioned and stained for histological analysis.

(A) Representative pictures of sections after Alcian blue stain and MUC5AC immunofluorescence (scale bar $=20 \mu \mathrm{m})$. Graphs representing (A) qPCR analysis for Muc5ac are shown. (B) Representative images of sections after transferase dUTP nick end-labelling (TUNEL) (green) and DAPI (blue) staining from airway and alveolar regions of the lung (scale bar $=20 \mu \mathrm{m}$ ). Percentage of TUNEL-positive cells quantified in each group and caspase 3/7 activity in lung tissue lysate are also shown. LU, luminescence units. Graphs are represented as mean \pm SEM of three measurements. $p$ Values shown, comparing both treatments connected by a line. All $n \geq 5$ per group. The comparisons between two individual groups were determined by Student's t-test. DAPI, 4',6-diamidino-2phenylindole.
A
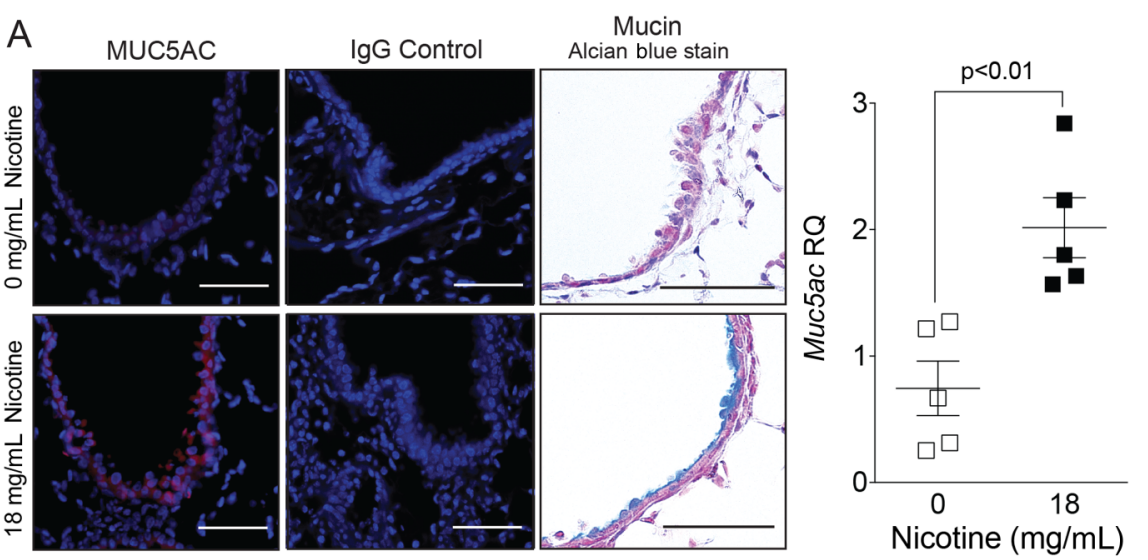

B

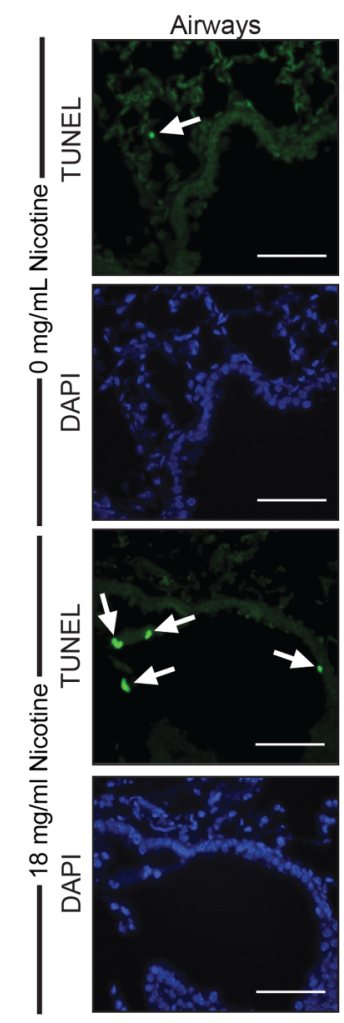

Alveoli
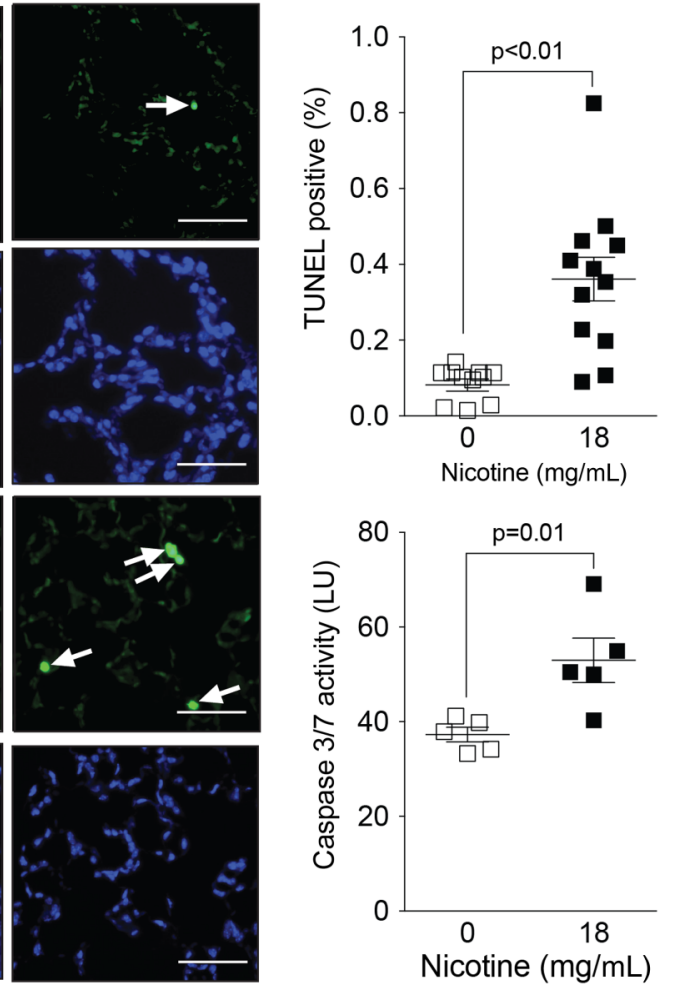

a trend towards an increase in the apical wash (figure 8D). In the media, IL- 6 and IL- 8 were significantly elevated by $10 \mu \mathrm{M}$ nicotine exposures and MCP-1 trended towards an increase in nicotine-exposed cells (figure $8 \mathrm{E}$ ). Together, these data suggest that nicotine exposure directly impacts parameters of mucociliary function and promotes a pro-inflammatory state in NHBE cells.

\section{DISCUSSION}

The Royal College of Physicians in the UK has recently advocated that switching to e-cigarettes will aid smoking cessation and reduce harm from conventional cigarette use. ${ }^{26}$ Indeed, it is well established that e-cigarettes produce less environmental pollutants, lack harmful tar and contain far fewer cancer-causing chemicals. ${ }^{9} 27$ Public health experts have argued that e-cigarettes will save lives by reducing or eliminating exposure to harmful cigarette components. This position, however, remains controversial as scientific data about the effects of e-cigarettes are lacking. Indeed, the Food and Drug Administration in the USA has announced that it will begin regulating e-cigarette products.
This study shows for the first time that e-cigarettes induce pathogenic responses akin to what occurs in human COPD. Even more importantly, it demonstrates that nicotine is the key component responsible for these pathogenic changes in the lung. While e-cigarette usage may potentially cause less cancer and vascular disease compared with conventional cigarettes, our data indicate that it will still promote the development of obstructive airways disease. Thus, the findings from this study should be taken into consideration when advising patients on possible health risks of these products.

Traditionally, nicotine has been studied as the addictive component of cigarettes, but increasing evidence indicates that nicotine is also a key factor in the initiation and progression of COPD. Nicotine hinders the hydration of mucus, ${ }^{28}$ promotes $\mathrm{Ca}^{2+}$ influx in airway smooth muscle cells, ${ }^{29}$ blocks neutrophil apoptosis $^{30}$ and induces pro-inflammatory dendritic cell responses. ${ }^{31}$ Smoke generated from high-dose nicotine cigarettes induces more emphysematous changes than low-dose nicotine cigarettes, in elastase-treated rats. ${ }^{32}$ The lack of focus on nicotine in this disease is surprising since genetic analyses identified 
A

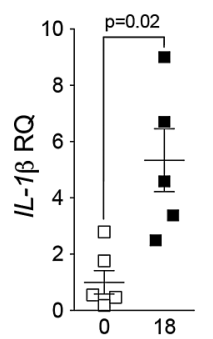

Nicotine $(\mathrm{mg} / \mathrm{mL})$
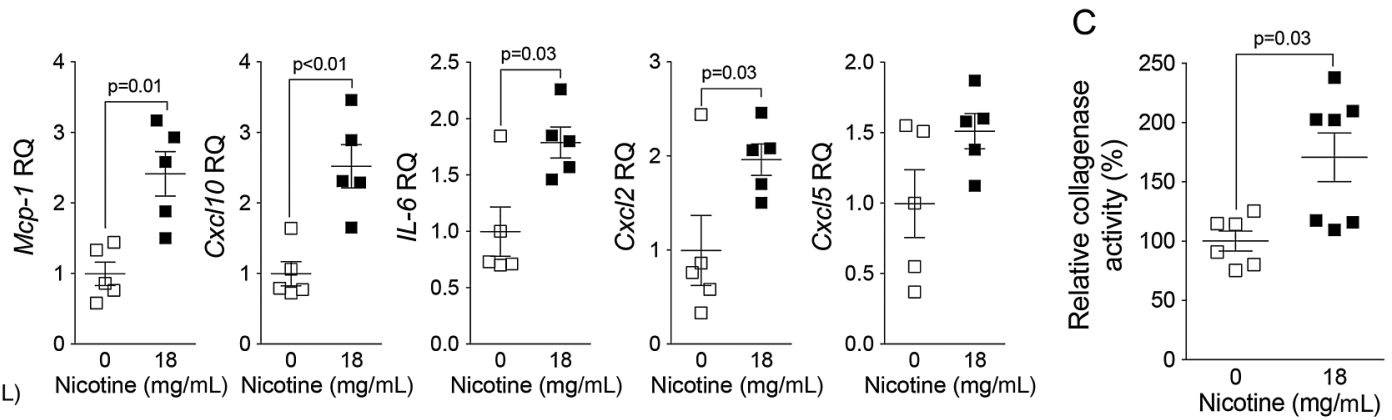

B
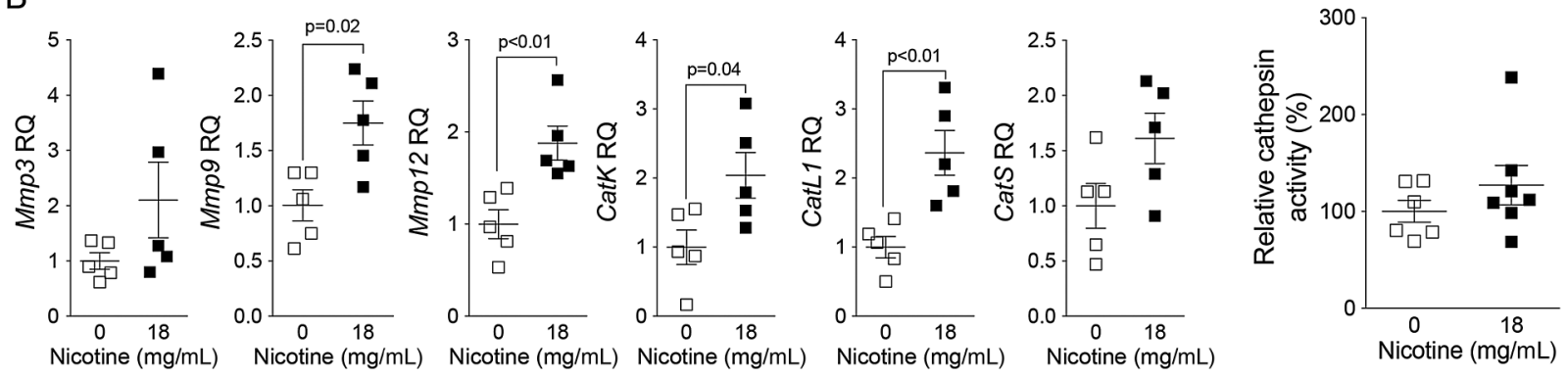

Figure 4 Cytokine and protease expression and activity in lungs from mice exposed to nicotine-free or nicotine-containing e-cigarette fluids. Mice were exposed to inhaled nicotine-free $(0 \mathrm{mg} / \mathrm{mL})$ or to nicotine-containing $(18 \mathrm{mg} / \mathrm{mL})$ e-cigarette fluid for 4 months. Gene expression analysis by qPCR for (A) the cytokines IL-1 $\beta, M C P-1, C X C L 10, I L-6, C X C L 2$ and CXCL5 and (B) proteases MMP-3, MMP-9, MMP-12, CatK, CatL1 and CatS. (C) Collagenase and cathepsin activity were measured in lung bronchoalveolar lavage fluid. Graphs are represented as mean $\pm S E M$ of three measurements. $p$ Values shown, comparing both treatments connected by a line. All $n \geq 5$ per group. The comparisons between two individual groups were determined by Student's t-test.

nicotinic receptors ( $\alpha 3 \mathrm{nAchR}$ and $\alpha 5 \mathrm{nAchR})$ as susceptibility loci for COPD. ${ }^{33}$ Moreover, nicotine makes up almost $3 \%$ of the dry weight of a tobacco leaf and smokers breathe in $42 \mathrm{mg}$ nicotine/day. ${ }^{34}$ Once absorbed, nicotine binds to nicotinic acetylcholine receptor (nAchRs). The airway epithelium expresses $\alpha 3, \alpha 4, \alpha 5, \alpha 7, \alpha 9, \beta 2$ and $\beta 4$ subunits for nAchRs, ${ }^{35}$ and their expression are highest on the apical cell surface, where exposure to inhaled nicotine occurs. ${ }^{36}$ In bronchiole cells, nicotine acted via $\alpha 7 A$ chR to upregulate $\gamma$-aminobutyric acid $(\mathrm{GABA})_{\mathrm{A}} \mathrm{R} \alpha 2$ and induces $M u c 5 a c$ expression and mucus production. ${ }^{37}$ This effect would explain the increased mucin staining and Muc5ac expression detected in mouse lungs following exposure to nicotine-containing e-cigarettes. Interestingly, CFTR and $\mathrm{BK}$ ion conductance and $\mathrm{CBF}$ were more negatively affected at a greater magnitude in cells exposed to aerosolised nicotine compared with cells where nicotine was supplemented in media. This indicates that apical exposure could be more detrimental than basolateral exposure. This occurred despite the fact that the concentration of nicotine was actually higher in the media $(10 \mu \mathrm{M})$ compared with the ASL $(60-120 \mathrm{nM})$ of the aerosol-exposed cells. This would suggest that inhaled nicotine impacts on the lungs differently than nicotine circulating in the body. However, further studies are needed to compare the pulmonary consequences of inhaled nicotine versus nicotine
A

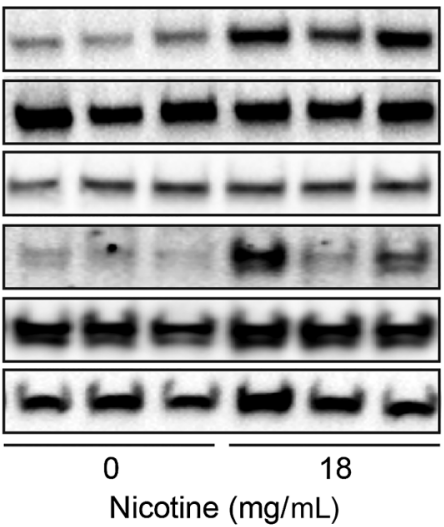

B

p-PKC $\alpha$
PKC $\alpha$
$\beta$-Actin
p-ERK
ERK
$\beta-A c t i n$
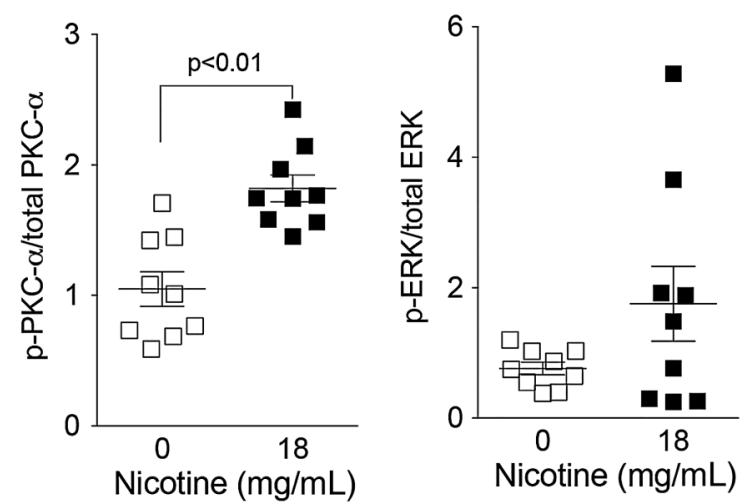

Figure 5 PKC $\alpha$ and ERK activation in the lungs of mice exposed to inhaled vehicle or nicotine-containing e-cigarette fluid. Mice were exposed daily to inhaled nicotine-free $(0 \mathrm{mg} / \mathrm{mL})$ or to nicotine-containing $(18 \mathrm{mg} / \mathrm{mL})$ e-cigarette fluid for $4 \mathrm{months}$. (A) Representative western blots for total and phosphorylated PKC $\alpha(p-P K C \alpha)$ and ERK in lung tissue homogenates. $\beta$-Actin was used as a loading control. (B) Optical intensity quantification and calculated ratios of phosphorylated/total protein for PKC $\alpha$ and ERK. Graphs are represented as mean \pm SEM of three measurements. $p$ Values shown, comparing both treatments connected by a line. All $n=9$ per group for densitometry analysis. The comparisons between two individual groups were determined by Student's t-test. 
A

e-Cigarettes vapor

(0 or $36 \mathrm{mg} / \mathrm{mL}$ Nicotine)

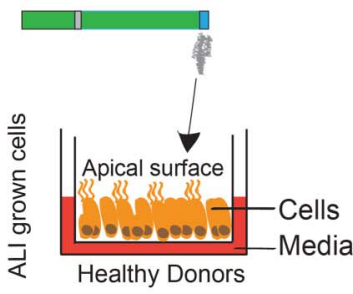

B

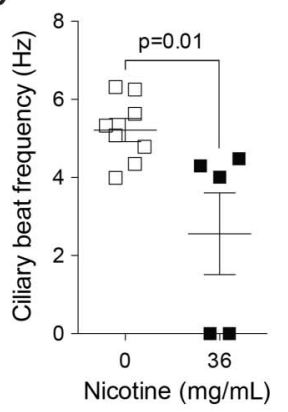

C

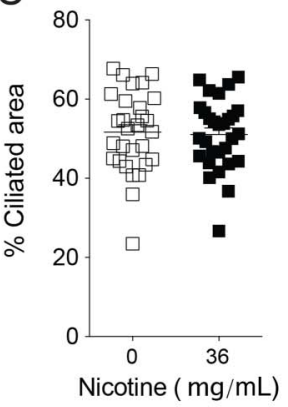

D

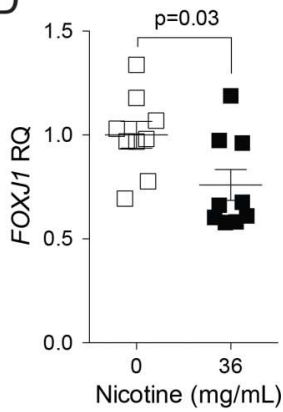

E

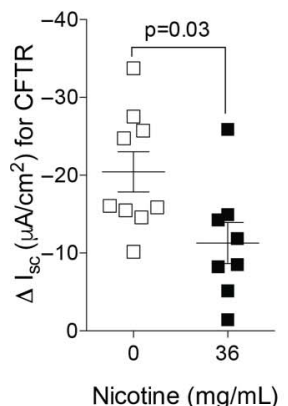

F

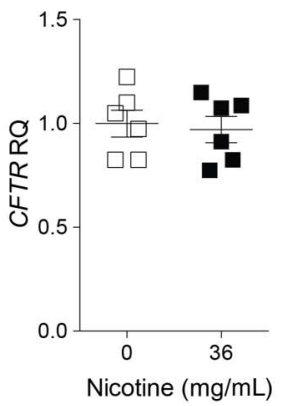

G

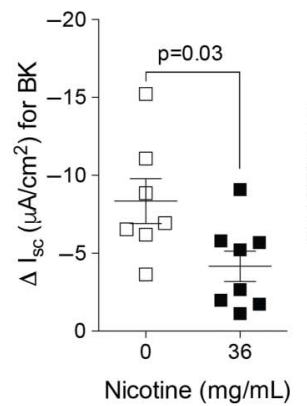

$\mathrm{H}$

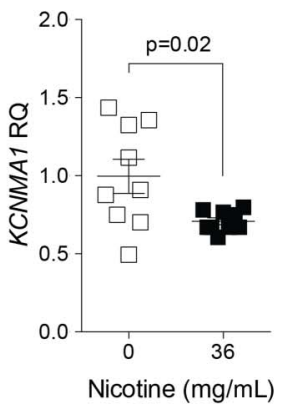

I

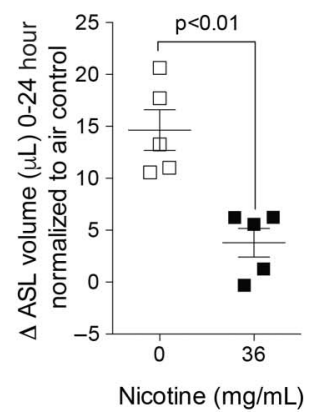

Figure 6 Effects of vehicle and nicotine-containing e-cigarette vapour on normal human bronchial epithelial (NHBE) cells. (A) Scheme showing how fully differentiated NHBE cells, grown at an air-liquid interface (ALI), were exposed to vapour from vehicle $(0 \mathrm{mg} / \mathrm{mL}) \mathrm{or}$ from nicotine-containing (36 mg/mL) e-cigarettes. (B) Ciliary beat frequency significantly decreased after exposure to nicotine-containing e-cigarette vapour. (C) Cells were stained with DAPI and antiacetylated tubulin to visualise cilia, 24 hours after exposures. The \% ciliated area was determined using ImageJ software. (D) qPCR for gene expression of FOXJ1. (E) Cystic fibrosis transmembrane regulator (CFTR) ion conductance is significantly decreased after exposure to nicotine-containing e-cigarette vapour. (F) qPCR for gene expression of CFTR. (G) ATP-stimulated K+ (BK) ion conductance is significantly decreased after exposure to nicotine-containing e-cigarette vapour. $(\mathrm{H}) \mathrm{qPCR}$ for gene expression of the $\alpha$ subunit of the BK channel (KCNMA1). (I) Measurement of airway surface liquid volume changes by refraction light microscopy. Graphs are represented as mean \pm SEM. $p$ Values shown, comparing both treatments connected by a line. All $n \geq 5$ per group. The comparisons between two individual groups were determined by Student's t-test.

A

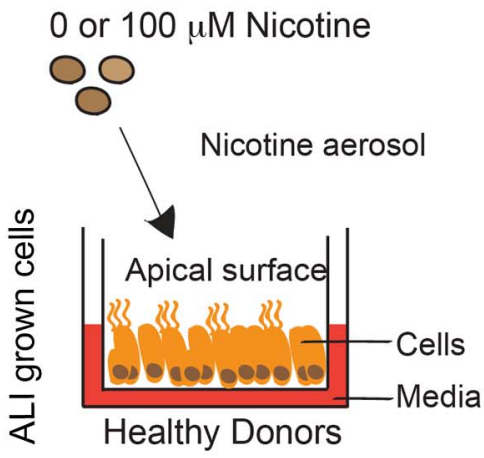

$\mathrm{B}$

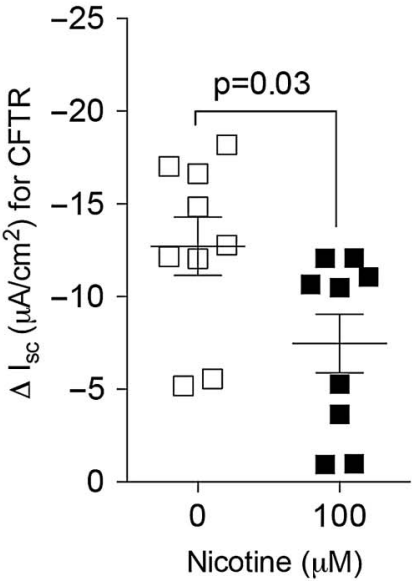

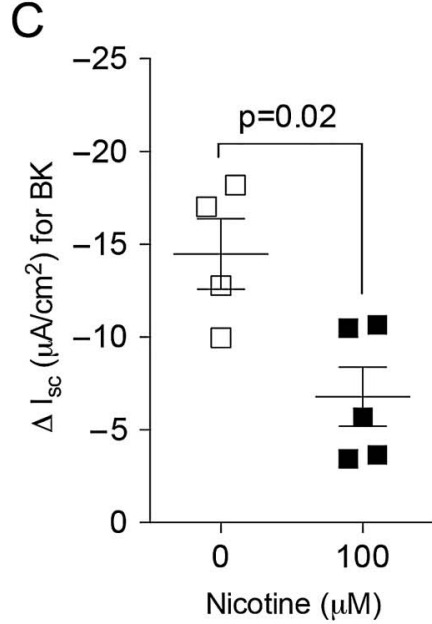

Figure 7 Effects of aerosolised nicotine on normal human bronchial epithelial (NHBE) cells. (A) Scheme showing how fully differentiated NHBE cells, grown at an air-liquid interface (ALI), were exposed to aerosolised saline containing 0 or $100 \mu \mathrm{M}$ nicotine. Final concentration of nicotine in the airway surface liquid was estimated between 60 and $120 \mathrm{nM}$ by microbalance deposition measurements. (B) Cystic fibrosis transmembrane regulator (CFTR) and (C) ATP-stimulated K+ (BK) ion conductances are significantly decreased in nicotine-exposed cell cultures compared with nicotine-free saline. Graphs are represented as mean \pm SEM. $p$ Values shown, comparing both treatments connected by a line. All $n \geq 4$ per group. The comparisons between two individual groups were determined by Student's t-test. 
A

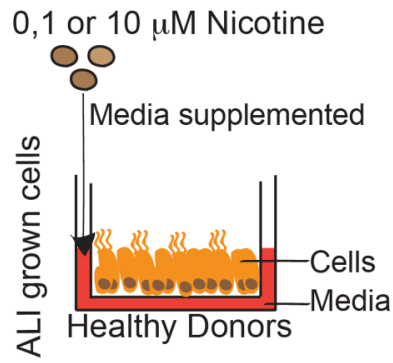

$\mathrm{D}$

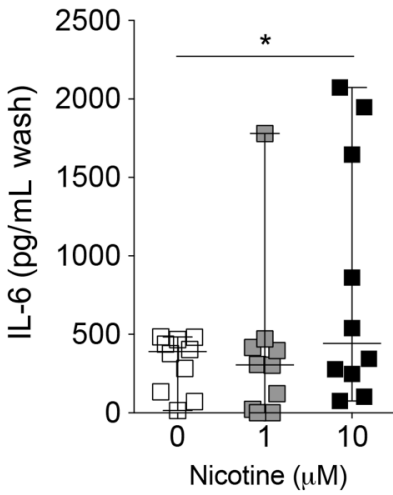

E

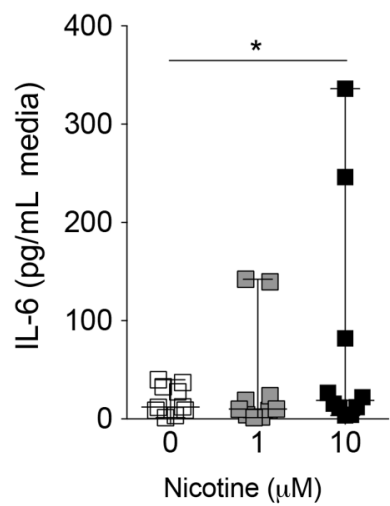

B
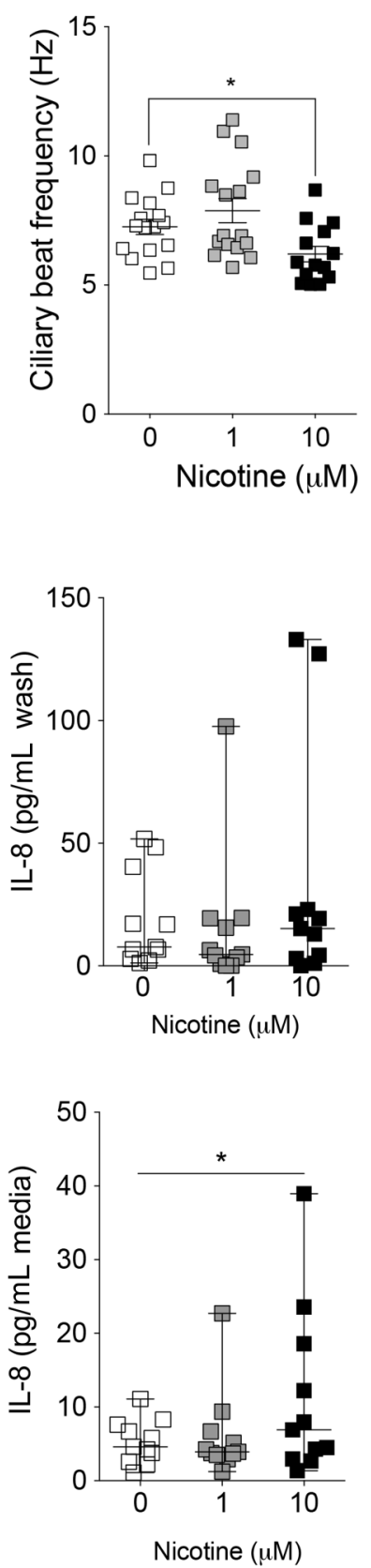

C
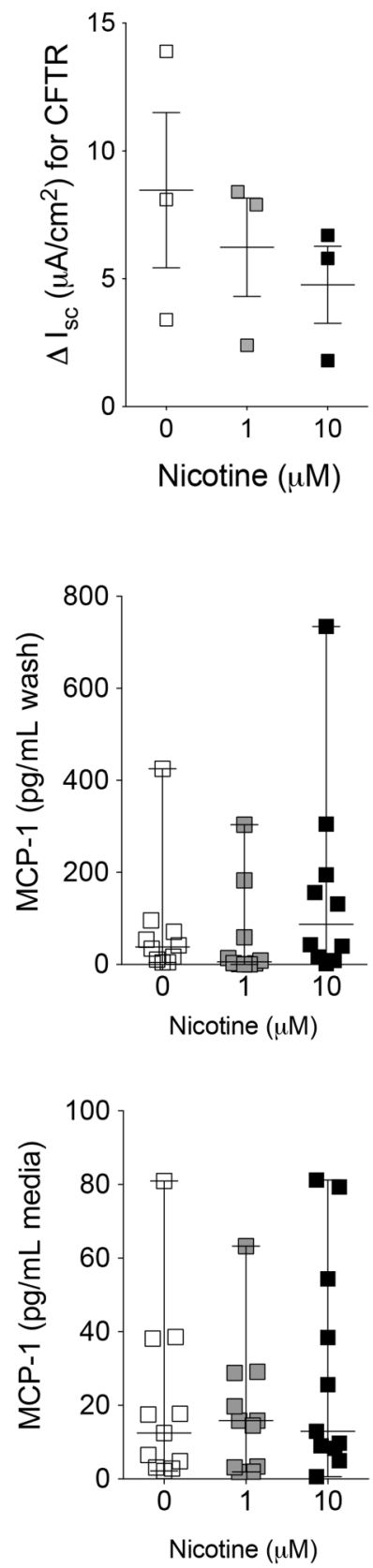

Figure 8 Cystic fibrosis transmembrane regulator (CFTR) conductance, ciliary beat frequency (CBF) and cytokine expression in normal human bronchial epithelial (NHBE) cells exposed to basolateral nicotine. (A) Differentiated NHBE cells, grown at an air-liquid interface (ALI), were exposed to nicotine $(0,1$ and $10 \mu \mathrm{M})$ basolaterally. (B) CBF and (C) CFTR ion conductance measurements were performed 12 hours after exposure. Graphs are represented as mean \pm SEM. One-way analysis of variance was used to compare the time-course curves and multiple comparisons were determined by the Dunn's method. (D-E) NHBE cells were exposed to culture media with or without nicotine for 5 days as outlined in Methods section. The concentration of interleukin (IL)-6, IL-8 and MCP-1 was measured in the apical wash (D) and in the basolateral media (E) following 5 days of exposure to culture media with or without nicotine. Graphs are represented as median \pm range. $p$ Values shown, comparing both treatments connected by a line; $n \geq 3$ per group. (D-E) Data sets were analysed by non-parametric Friedman tests.

absorbed systemically though products like nicotine patches. Though nicotine acts via $\alpha 7 \mathrm{nAchR}$ to stimulate $\mathrm{PKC} \alpha$ (see figure 9 for potential signalling), it remains to be determined how much PKC $\alpha$ activation contributed to the pathogenic changes that occurred in our lung models. Indeed, identifying the signalling mechanisms responsible for these nicotinemediated effects will be a key goal of future studies.

Other in vitro and in vivo studies that showed that short-term e-cigarette vapour inhalation alters lung inflammatory responses. ${ }^{78}$ To date, no other studies have looked at the effects of chronic e-cigarette exposure on lung inflammation in mice. Unlike our study and the study by Lerner et al, ${ }^{7}$ Sussan $e t a l^{8}$ did not identify increases in IL-6 or MCP-1 in response to e-cigarette exposure but this may be accounted for by differences in mouse background, exposure time, e-cigarette flavouring, cotinine levels in plasma and the presence of a pulmonary infection. ${ }^{8}$ In ova-albumin sensitised mice, a 10 -week e-cigarette exposure was reported to increase airway hyper-reactivity ${ }^{38}$ and 


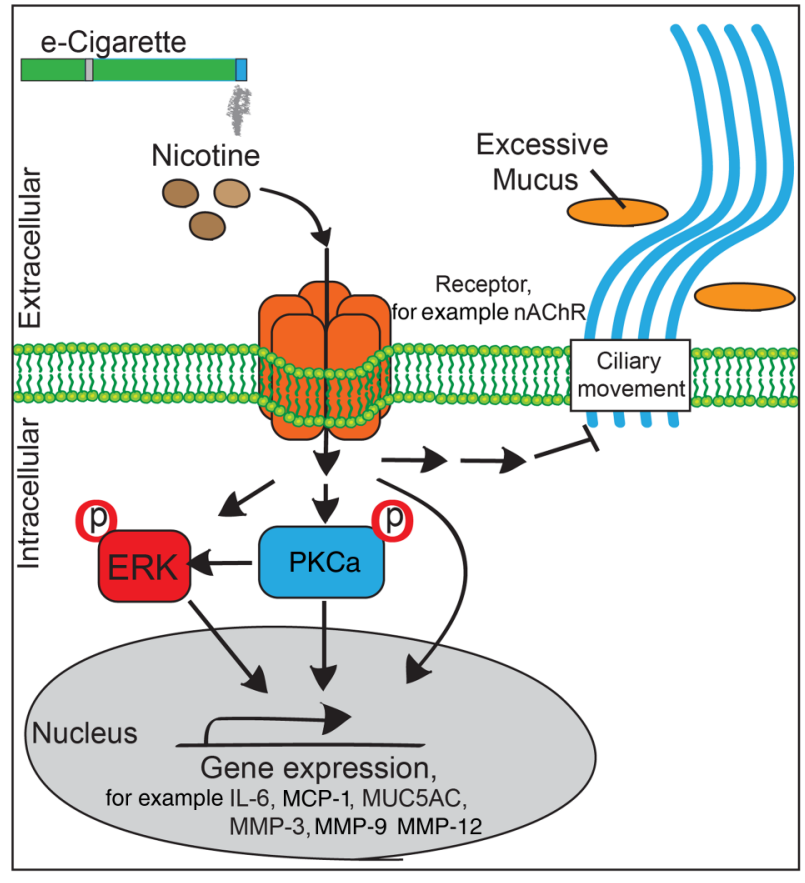

Figure 9 Possible signalling mechanism for nicotine-containing e-cigarette-induced lung damage. ERK, extracellular regulated kinase; IL, interleukin; $\mathrm{nAChR}$, nicotinic acetylcholine receptor.

we found that chronic e-cigarette inhalation, by itself, induces airway hyper-reactivity. Similar to cigarette smoke, nicotine in e-cigarettes promotes airway smooth muscle proliferation and contraction, which can impact airway hyper-reactivity in exposed individuals. ${ }^{39}$ Thus, nicotine could be a key factor driving the onset and progression of lung disease.

Commercially available, nicotine-free, vehicle was used as a control for the nicotine-containing e-cigarette liquid. With the exception of nicotine, the composition of these two liquids was identical. We chose to investigate a vehicle (50:50 PG:VG) that is commonly used by e-cigarette users. To avoid potential confounding effects, we also elected to use a vehicle that did not contain flavouring since the additives in e-cigarette flavourings induce significant oxidative and inflammatory responses in lung cells and tissues. ${ }^{7}$ This study observed no deleterious effects of the vehicle, but the authors cannot rule out the potential longterm side effects of components in a wide variety of commercially available e-liquids. Indeed, recent e-cigarette studies found substantial detectable levels of toxic metals, such as aluminium, copper, zinc, lead and chromium. ${ }^{40}$

In summary, these results show the adverse lung health effects of chronic e-cigarette exposure. In addition, they establish that nicotine is the key component that causes airway hyperreactivity and lung tissue destruction. e-Cigarettes contain far fewer carcinogens and are less likely to promote carcinogenesis. Thus, though e-cigarettes may have a better safety profile, refraining from nicotine inhalation will likely impact on preserving lung health.

\footnotetext{
Author affiliations

${ }^{1}$ Division of Pulmonary and Critical Care Medicine, SUNY Downstate Medical Center, Brooklyn, New York, USA

${ }^{2}$ Department of Cell Biology, State University of New York Downstate Medical Center, Brooklyn, New York, USA

${ }^{3}$ Division of Pulmonary, Allergy, Critical Care and Sleep Medicine, University of Miami Miller School of Medicine, Miami, Florida, USA

${ }^{4}$ Department of Medicine, Royal College of Surgeons in Ireland, Dublin, Ireland
}

${ }^{5}$ Division of Pulmonary, Critical Care and Sleep Medicine, Mount Sinai St. Luke's Roosevelt Health Sciences Center, New York, New York, USA

Acknowledgements The authors thank Dr Moro Salifu and Dr Gerard Turino and the James P. Mara Center for Lung Disease and Ruth Unger and the Mah Jongg Foundation League for their support and guidance. They also acknowledge Michael Myerburg (University of Pittsburgh) for making meniscus scanning software for airway surface liquid volume estimation available.

Contributors IG-A and PG: responsible for study design and execution, data collection and manuscript preparation. NB, MC, AJD, BJ, NC, AG and EE: responsible for study execution. MS: responsible for study design and execution and manuscript preparation. RF: responsible for study design, execution, data collection and overall manuscript preparation. He is the guarantor.

Funding This work was supported by grants made available to RF (Flight Attendant Medical Research Institute YCSA 24039, CIA 074047 and the US National Institutes of Health 1R01HL098528-05), MS (Flight Attendant Medical Research Institute, CIA 130033 and the James and Esther King Florida Biomedical Research Program grant\#5JK02), PG (Flight Attendant Medical Research Institute YCSA 113380) and IG-A (Flight Attendant Medical Research Institute YCSA 13005).

Competing interests None declared.

Provenance and peer review Not commissioned; externally peer reviewed.

Open Access This is an Open Access article distributed in accordance with the Creative Commons Attribution Non Commercial (CC BY-NC 4.0) license, which permits others to distribute, remix, adapt, build upon this work non-commercially, and license their derivative works on different terms, provided the original work is properly cited and the use is non-commercial. See: http://creativecommons.org/ licenses/by-nc/4.0/

\section{REFERENCES}

1 Murphy BS, Xu J, Kochanek KD. Deaths: preliminary data for 2010. In: Reports National Vital Statistics Report, ed. Hyattsville, MD: National Center for Health Statistics, 2012:61(4).

2 Raherison C, Girodet PO. Epidemiology of COPD. Eur Respir Rev 2009;18:213-21.

3 Centers for Disease Control and Prevention (CDC). Cigarettes smoking among adults-United States, 2011. MMWR Morb Mortal Wkly Rep 2012;61:889-94.

4 US. Treating tobacco use and dependence: clinical practice guideline. In: Services DoHaH, ed. Department of Health and Human Services 2008 Report. 2008;1-32.

5 Bullen C, Williman J, Howe C, et al. Study protocol for a randomised controlled trial of electronic cigarettes versus nicotine patch for smoking cessation. BMC Public Health 2013;13:210.

6 Schroeder MJ, Hoffman AC. Electronic cigarettes and nicotine clinical pharmacology. Tob Control 2014;23(Suppl 2):ii30-5.

7 Lerner CA, Sundar IK, Yao H, et al. Vapors produced by electronic cigarettes and e-juices with flavorings induce toxicity, oxidative stress, and inflammatory response in lung epithelial cells and in mouse lung. PLOS ONE 2015;10:e0116732.

8 Sussan TE, Gajghate S, Thimmulappa RK, et al. Exposure to electronic cigarettes impairs pulmonary anti-bacterial and anti-viral defenses in a mouse model. PLOS ONE 2015;10:e0116861.

9 Schober W, Szendrei K, Matzen W, et al. Use of electronic cigarettes (e-cigarettes) impairs indoor air quality and increases FeNO levels of e-cigarette consumers. Int J Hyg Environ Health 2014;217:628-37.

10 Xu Y, Zhang Y, Cardell LO. Nicotine exaggerates LPS-induced airway hyperreactivity via JNK-mediated up-regulation of toll-like receptor 4. Am J Respir Cell Mol Biol 2014;51:370-9.

11 Paleari L, Catassi A, Ciarlo M, et al. Role of alpha7-nicotinic acetylcholine receptor in human non-small cell lung cancer proliferation. Cell Prolif 2008;41:936-59.

12 Geraghty P, Hardigan A, Foronjy RF. Cigarette smoke activates the proto-oncogene c-src to promote airway inflammation and lung tissue destruction. Am J Respir Cell Mol Biol 2014;50:559-70.

13 Foronjy RF, Mirochnitchenko 0, Propokenko 0, et al. Superoxide dismutase expression attenuates cigarette smoke- or elastase-generated emphysema in mice. Am J Respir Crit Care Med 2006;173:623-31.

14 Geraghty P, Wyman AE, Garcia-Arcos I, et al. STAT3 modulates cigarette smoke-induced inflammation and protease expression. Front Physiol 2013;4:267.

15 Moore S, Stein WH. Chromatography of amino acids; colorimetric ninhydrin method for analysis of the effluent. Fed Proc 1948;7(1 Pt):174.

16 Geraghty P, Greene CM, O'Mahony M, et al. Secretory leucocyte protease inhibitor inhibits interferon-gamma-induced cathepsin S expression. J Biol Chem 2007;282:33389-95.

17 Schmid A, Sutto Z, Nlend MC, et al. Soluble adenylyl cyclase is localized to cilia and contributes to ciliary beat frequency regulation via production of CAMP. J Gen Physiol 2007;130:99-109.

18 Conner GE, Wijkstrom-Frei C, Randell SH, et al. The lactoperoxidase system links anion transport to host defense in cystic fibrosis. FEBS Lett 2007;581:271-8. 
19 Monzon ME, Fregien N, Schmid N, et al. Reactive oxygen species and hyaluronidase 2 regulate airway epithelial hyaluronan fragmentation. J Biol Chem 2010;285:26126-34.

20 Manzanares D, Srinivasan M, Salathe ST, et al. IFN-gamma-mediated reduction of large-conductance, Ca2+-activated, voltage-dependent $\mathrm{K}+(\mathrm{BK})$ channel activity in airway epithelial cells leads to mucociliary dysfunction. Am J Physiol Lung Cell Mol Physiol 2014;306:L453-62.

21 Demedts IK, Demoor T, Bracke KR, et al. Role of apoptosis in the pathogenesis of COPD and pulmonary emphysema. Respir Res 2006;7:53.

22 Geraghty P, Hardigan AA, Wallace AM, et al. Cigarette smoke activates the proto-oncogene c-Src to promote airway inflammation and lung tissue destruction. Am J Respir Cell Mol Biol 2013;49:721-30.

23 Maneckjee R, Minna JD. Opioids induce while nicotine suppresses apoptosis in human lung cancer cells. Cell Growth Differ 1994;5:1033-40.

24 Kazimierová I, Jošková M, Pecháňová 0 , et al. Effects of provinol and its combinations with clinically used antiasthmatics on airway defense mechanisms in experimental allergic asthma. Adv Exp Med Biol 2015;838:27-34.

25 Manzanares D, Gonzalez C, Ivonnet $P$, et al. Functional apical large conductance, $\mathrm{Ca} 2+$-activated, and voltage-dependent $\mathrm{K}+$ channels are required for maintenance of airway surface liquid volume. J Biol Chem 2011;286:19830-9.

26 Physicians RCo. Nicotine without smoke: Tobacco harm reduction. London: Royal College of Physicians, 2016;1-191.

27 Czogala J, Goniewicz ML, Fidelus B, et al. Secondhand exposure to vapors from electronic cigarettes. Nicotine Tob Res 2014;16:655-62.

28 Chen EY, Sun A, Chen CS, et al. Nicotine alters mucin rheological properties. Am J Physiol Lung Cell Mol Physiol 2014;307:L149-57.

29 Jiang $Y$, Dai $A$, Zhou $Y$, et al. Nicotine elevated intracellular $\mathrm{Ca}(2)(+)$ in rat airway smooth muscle cells via activating and up-regulating alpha7-nicotinic acetylcholine receptor. Cell Physiol Biochem 2014;33:389-401.

30 Xu Y, Li H, Bajrami B, et al. Cigarette smoke (CS) and nicotine delay neutrophil spontaneous death via suppressing production of diphosphoinositol pentakisphosphate. Proc Natl Acad Sci USA 2013;110:7726-31.
31 Vassallo R, Kroening PR, Parambil J, et al. Nicotine and oxidative cigarette smoke constituents induce immune-modulatory and pro-inflammatory dendritic cell responses. Mol Immunol 2008;45:3321-9.

32 Diamond L, Kimmel EC, Lai YL, et al. Augmentation of elastase-induced emphysema by cigarette smoke: effects of reduced nicotine content. Am Rev Respir Dis 1988; 138:1201-6.

33 Pillai SG, Kong $X$, Edwards LD, et al. Loci identified by genome-wide association studies influence different disease-related phenotypes in chronic obstructive pulmonary disease. Am J Respir Crit Care Med 2010;182: 1498-505.

34 Djordjevic MV, Stellman SD, Zang E. Doses of nicotine and lung carcinogens delivered to cigarette smokers. J Natl Cancer Inst 2000;92: 106-11.

35 Zia S, Ndoye A, Nguyen VT, et al. Nicotine enhances expression of the alpha 3, alpha 4, alpha 5, and alpha 7 nicotinic receptors modulating calcium metabolism and regulating adhesion and motility of respiratory epithelial cells. Res Commun Mol Pathol Pharmacol 1997;97:243-62.

36 Maouche K, Polette M, Jolly T, et al. \{alpha\}7 nicotinic acetylcholine receptor regulates airway epithelium differentiation by controlling basal cell proliferation. Am J Pathol 2009;175:1868-82.

37 Gundavarapu S, Wilder JA, Mishra NC, et al. Role of nicotinic receptors and acetylcholine in mucous cell metaplasia, hyperplasia, and airway mucus formation in vitro and in vivo. J Allergy Clin Immunol 2012;130:770-80.e11.

$38 \mathrm{Lim} \mathrm{HB}$, Kim SH. Inhalation of e-cigarette cartridge solution aggravates allergen-induced airway inflammation and hyper-responsiveness in mice. Toxicol Res 2014;30: 13-18.

39 Xu GN, Yang K, Xu ZP, et al. Protective effects of anisodamine on cigarette smoke extract-induced airway smooth muscle cell proliferation and tracheal contractility. Toxicol Appl Pharmacol 2012;262:70-9.

40 Williams M, Villarreal A, Bozhilov K, et al. Metal and silicate particles including nanoparticles are present in electronic cigarette cartomizer fluid and aerosol. PLOS ONE 2013;8:e57987. 